\title{
Abuso de SubstÂNCIAS GÊMEAS: PAP E KUHN CONTRA A DISTINÇÃO ENTRE PROPRIEDADES ESSENCIAIS E ACIDENTAIS DE ESPÉCIES CIENTÍFICAS
}

Twin substances abuse: PAP AND KuHN Against the Distinction BetWeEn ESSENTIAL AND ACCIDENTAL PROPRIETIES OF SCIENTIFIC KINDS

\author{
JEFERSON HUFFERMANN \\ Universidade Federal do Rio Grande do Sul, BRASIL \\ jeferson.diello@gmai.com
}

\begin{abstract}
In this paper I give a critical assessment of the essentialism about natural kinds using the functional theory of the a priori by Arthur Pap (1943; 1944; 1946). In a manner similar to authors that uphold the primacy of scientific practice, reasons are given to reject the legitimacy of a distinction between essential and accidental proprieties inside of a scientific theory. We aim to show how an answer very similar to Thomas Kuhn's to the famous Twin Earth experiment can be formulated using Pap's functional theory. Both Kuhn and Pap give reasons to reject the causal theory of reference to the scientific lexicon. Having as basis an analysis of scientific practice from the first half of 20th century, we show how the distinction between accidental and essential proprieties is inadequate (the case of the "Twin Phosphorus"). This allows us to bring together the functional theory of the a priori and the "historical turn" in Philosophy of Science found in authors like Kuhn, showing also how this process was more continuous than originally thought.
\end{abstract}

Keywords: History of philosophy of science $\bullet$ function theory of the a priori $\bullet$ Arthur Pap $\bullet$ Thomas Kuhn $\bullet$ accidental proprieties and essential proprieties

\section{Introdução}

Há diálogos platônicos, como Fedro (264e-265e) e Político (286d-287e), nos quais encontramos a ideia "de cortar a natureza em suas juntas". Considerando essa imagem valiosa, a tarefa epistêmica seria análoga àquela do açougueiro, que identifica as juntas do animal e corta a carne de modo a aproveitá-la ao máximo. A metáfora sugere uma certa categorização inata da natureza que devemos identificar para então manipulá-la. Uma forma comum de se pensar nessas categorias é através da distinção entre gênero e espécie. Um caso simples e banal de uso da distinção é ilustrativo: Pica-pau é uma espécie de pássaro que é uma espécie de animal que é uma espécie de ser vivo. A frase anterior é um exemplo curto de taxonomia. Trata-se de uma classificação que parte de espécies mais gerais (gêneros) em direção a espécies particulares, 
de modo finito e não circular (há uma espécie que não é gênero de outra espécie). Podemos nos perguntar acerca da motivação para criar taxonomias e outras formas de classificação como essa. Uma resposta possível, em concordância com a metáfora das juntas da natureza, é aquela que afirma que as propriedades que determinam a categoria "pássaro" são as propriedades essenciais de tudo aquilo que possa a vir a ser corretamente identificado como um pássaro. A espécie, seja mais geral ou mais particular, é um agregado de certas propriedades essenciais. Ao partir dessa suposição metafísica, nossas práticas epistêmicas (ou ao menos algumas delas) seriam compreendidas como uma progressiva e ampliativa descoberta das propriedades essenciais que fazem com que algo seja de uma determinada espécie.

Considere a espécie "água": afirmações como "Água é $\mathrm{H}_{2} \mathrm{O}$ " identificariam propriedades essenciais, portanto, expressariam verdades necessárias (nos diriam o que algo é e não poderia deixar de ser para continuar a ser aquilo que é). Contudo, não é inconcebível que água tivesse uma fórmula química distinta daquela que tem, que poderia ter uma fórmula química muito extensa abreviada como " $X Y Z$ ". Consequentemente, "Água é $\mathrm{H}_{2} \mathrm{O}$ ", se verdadeiro, não tem o mesmo estatuto que proposições como " $1=1$ ". Se água é $\mathrm{H}_{2} \mathrm{O}$, qualquer coisa que venha a ser corretamente identificada como água tem essa fórmula química, mas não incorremos em contradições ao pensar que a fórmula química da água poderia ser outra. Mesmo que concebível, não se segue disso que seria possível. Como veremos, ambos Pap e Kuhn defendem alguns balizamentos no que é cientificamente possível que vão além da mera conceptibilidade. $^{1}$

Mas retornando a água e sua fórmula química: ter a fórmula química $\mathrm{H}_{2} \mathrm{O}$ é a única propriedade essencial da água? Se sim, as demais propriedades (ser incolor, inodora, matar a sede) seriam acidentais. Nesse caso, seria legítimo considerar a possibilidade de uma substância com todas as propriedades acidentais da água, mas como uma diferente composição química. Uma água* que é incolor, inodora, mata a sede, mas tem uma fórmula química distinta. Generalizando esse caso para o empreendimento científico seríamos forçados a entender a ciência como o desvelamento de essências, o modo pelo qual distinguimos propriedades acidentais de propriedades essenciais. Em grande medida Kripke e Putnam, através de desenvolvimentos paralelos e distintos, defenderam teorias que dão suporte a uma imagem desse tipo. A contribuição, desejada ou não, é seus argumentos em favor da ampliação da teoria causal da referência a termos de espécies naturais. As ideias de ambos os autores ficaram conhecidas como "externalismo semântico" ou "teoria causal da referência".

Inicialmente pensada como uma perspectiva acerca da referência de nomes próprios, é mais simples explicá-la usando-os como exemplo. Nomes próprios de indivíduos como "Duda" se referem ou designam o mesmo indivíduo em qualquer mundo possível, a saber, o mesmo indivíduo que é designado pelo nome "Duda" no mundo atual. O nome "Duda", no presente contexto de proferimento, designa o companheiro 
do autor desse texto e o faz em qualquer cenário contrafactual imaginável. É possível afirmar, acerca dos nomes próprios, que eles designam o que designam de modo fixo e invariável. Podemos classificá-los, de acordo com o vocabulário técnico, como designadores rígidos. O nome "Duda" é um designador rígido por que foi introduzido para se referir apenas àquele indivíduo a que se refere e há uma cadeia histórico-causal que conecta o nome ao indivíduo (Kripke 1980, p.135). Trata-se de uma teoria causal da referência por considerar que o que estabelece o significado de um termo é a conexão causal entre o uso de tal termo e certas entidades. Kripke considera não problemático estender esse vocabulário acerca dos nomes próprios aos chamados "nomes comuns", espécies naturais como "vaca" e "tigre" (Kripke 1980, p.127). Putnam, com maior ênfase argumentativa, defendeu que a referência de termos como "planeta" e "água" é o que é fundamental para estabelecer o significado desses termos. O fato de Kripke considerar que essa posição não demanda uma argumentação rigorosa e cogente diz mais sobre o filósofo do que sobre suas teses. A ênfase maior de Putnam à qual me refiro diz respeito ao fato de que Kripke não apresenta argumentos substanciais em favor da tese de que nomes comuns designam rigidamente, essa tese é explicitada como consequência direta daquilo que é dito em favor da tese da designação rígida de nomes próprios. O autor afirma de maneira não problemática que "Em geral, a ciência tenta, ao investigar características estruturais básicas, encontrar a natureza, e desse modo a essência (no sentido filosófico) de tipos". (Kripke 1980, p.138). Como Putnam de fato oferece razões mais diretas e explícitas em favor da tese, analisaremos sua proposta.

Em algum sentido, com mais ou menos argumentos, esses autores defenderam que termos de espécies naturais, assim como nomes, designam rigidamente. A tese central desses autores relevante para a discussão proposta por este artigo é que a referência de termos designadores de espécies naturais não é fixada por uma descrição ou conjunto de descrições que determinam a extensão do termo, mas pela introdução de um termo linguístico (por exemplo, "água") para uma amostra da espécie. Assim como no caso de indivíduos, espécies naturais são batizadas. Um dos experimentos de pensamento mais célebres da história da filosofia contemporânea visa estabelecer essa tese. O experimento ficou conhecido como "Experimento da Terra Gêmea". Como exploraremos melhor na terceira seção, podemos entender o cientista da Terra e da Terra Gêmea, a partir do experimento de Putnam, como desvelando a essência dessas substâncias batizadas pelo termo "água" em seus respectivos planetas: água terráquea é $\mathrm{H}_{2} \mathrm{O}$ e água gêmea é $X Y Z$.

Uma noção diferente de progresso do conhecimento científico é encontrada em obras como A Estrutura das Revoluções Científicas ([1962] 2012) de Thomas Kuhn. Nessa obra o desenvolvimento da ciência é descrito como ocorrendo em ciclos sucessivos de ciência normal, crises, revoluções científicas e volta à ciência normal. Ciência normal é o período em que uma disciplina é guiada por um paradigma bem-sucedido 
e tal é o caso na maior parte da história da ciência. Crises ocorrem quando surgem, na prática científica, anomalias que o paradigma não consegue resolver. A persistência de anomalias leva a uma revolução científica, que resulta num novo paradigma e consequentemente novo período de ciência normal. A partir de exemplares de boas soluções de problemas teóricos encontrados no interior de disciplinas científicas o cientista avança a cada vez melhores soluções de novos problemas teóricos.

Nessa visão do empreendimento científico não avançamos em direção a algo (que poderia ser um conhecimento mais detalhado de essências), mas a partir de algo (as soluções reconhecidas como conquistas cognitivas motivam e guiam o desenvolvimento de soluções a problemas similares). Kuhn, em seu tratamento do aspecto revolucionário da mudança de paradigmas ocorrida ao longo do desenvolvimento das ciências naturais, fortalece uma tendência importante na história da filosofia da ciência: a chamada "virada histórica" em filosofia da ciência, uma tendência que em alguma medida antecede ao próprio Kuhn. Ao refletir sobre ela anos depois da Estrutura, reconhece que sua abordagem não era hegemônica, mas trata de recordar que não se encontrava sozinho. Kuhn (2003) menciona uma lista de nomes hoje consagrada: Paul Feyerabend, ${ }^{2}$ Russ Hanson, Mary Hesse, Michael Polanyi e Stephen Toulmin. O que proponho é que a teoria funcional do a priori de Arthur Pap (1943; 1944; [1946]1968) é uma abordagem que se aproxima de uma tendência metodológica descritivo-normativa de práticas epistêmicas bem-sucedidas que ganha força na "virada histórica" e é hoje hegemônica. As discussões contemporâneas negligenciam as contribuições desse antecessor que defendeu uma concepção do conhecimento científico similar aos autores e autoras da assim chamada virada histórica. Mostro neste artigo como tal antecessor ignorado pode ser reinserido em discussões filosóficas que marcaram o século $X X$ e reverberam até os nossos dias. A seguir apresentamos em linhas gerais a teoria funcional do a priori (seção 2). A partir dela e com o auxílio de ideias de Kuhn, analisaremos o experimento de pensamento de Putnam e um caso análogo pensado por Pap que denominamos "Fósforo Gêmeo". Feito isso, razões contrárias tanto à ampliação da teoria causal da referência às espécies naturais quanto ao essencialismo acerca de espécies naturais serão apresentadas.

\section{A teoria funcional do a priori de Arthur Pap}

Nessa seção propomos uma reconstrução e apropriação crítica do argumento central encontrado em The A Priori in Physical Theory (Pap 1968[1946]) em favor da teoria funcional do a priori (cf., para mais detalhes, Huffermann 2019a). Entretanto, a reconstrução dará ênfase maior aos casos da Física discutidos por Pap, explorando, sempre que pertinente, pormenores da teoria funcional do a priori que não fazem parte do argumento central. Trata-se de uma apropriação crítica pois consiste numa 
reconstrução dos argumentos de Arthur Pap que visa não apenas aclarar sua posição, mas aprimorá-la, explorando possibilidades de desenvolvimento ignoradas pelo autor. Isso se justifica ao atentarmos que as ideias oriundas da concepção funcional surgem do interior de uma reflexão acerca da prática científica, desse modo há uma forte concordância metodológica entre Pap e os autores já mencionados da assim chamada "virada histórica".

Pap elaborou sua teoria visando explicar os aspectos regulativos e descritivos que estamos dispostos a atribuir, prima facie, aos princípios que formam a base ou fundamento das ciências. Trata-se de uma concepção funcional do a priori pois o que se verifica é a rejeição de condições necessárias globais de acesso cognitivo a todo objeto possível da experiência (o que poderíamos denominar "a priori kantiano"); o que ele defende são condições locais de aplicação empírica de uma matriz teórica físico-matemática, critérios de intervenção, identificação e manipulação de fenômenos, próprios de um dado momento histórico. De acordo com sua abordagem, estaríamos autorizados a asserir os princípios das ciências da natureza dado que eles foram enrijecidos (fixados) ou entrincheirados num corpo coerente de conhecimento de modo a servir como critério para investigação futura.

Comparativamente, os princípios das ciências para Pap são projetáveis no sentido de Hacking (1993) e Goodman (1983). Um dado ramo científico de investigação não se preocupa apenas com o que é o caso, mas também com o que seria o caso em condições materiais diferentes. As "espécies naturais" empregadas nas teorias científicas são espécies relevantes de acordo com certos desejos, interesses e critérios de classificação. A ciência madura avança a partir de sofisticadas classificações que nos ajudam a entender, explicar, prever e intervir no curso da natureza (Hacking 1993, p.291). Em decorrência disso a comunidade científica projeta certos predicados, a saber, aqueles que a comunidade considera seriamente como possibilidades num dado estágio de desenvolvimento. Voltando a Arthur Pap, de maneira deveras econômica, pode-se dizer que os princípios das ciências seriam constitutivos dos fenômenos que visam explicar, de tal modo que a adesão a tais princípios é condição para sua inteligibilidade. $\mathrm{O}$ aspecto descritivo dos princípios, em geral, é explicado na primeira parte de The a priori in Physical theory quando os mesmos são considerados em conjunto, ao formarem uma rede conceitual que possibilita a confirmação de uns em função de outros (Pap 1968[1946], p.35). Um exemplo desse tipo de confirmação cruzada é dado ao examinarmos o que Pap chama de "funcionamento analítico" da Lei de Hooke.

A proposta de Pap foi somente marginalmente considerada, e encontra-se praticamente obliterada na história da filosofia contemporânea. Michael Friedman, na obra Dynamics of Reason (2001), em nota de rodapé, considera-a de pouca importância por ser demasiado semelhante ao empirismo quineano (Friedman 2001, p.88). É digno de destaque para nossos propósitos que Friedman defende em obras mais recentes 
uma versão dita mais histórica da tese defendida em 2001 (Friedman, 2010). A diferença entre o que defende o autor de Dynamics e Friedman (2010; 2011a; 2011b) não é traçada de maneira satisfatoriamente clara. O que é claro é que Friedman não se apresenta mais em total oposição à Quine; o neokantiano talvez pudesse retornar a autores ditos demasiadamente similares ao holista e reconhecer a fecundidade de suas propostas.

Para além de ser uma concepção que merece atenção por si só, a teoria funcional do a priori de Pap pode ser compreendida como ocasião em que se entrecruzam ideias advindas de distintas vertentes filosóficas, como o convencionalismo de $\mathrm{H}$. Poincaré, o pragmatismo de C. I. Lewis e J. Dewey, o Neokantismo de E. Cassirer e o pensamento de alguns integrantes do Círculo de Viena, como Schlick, Carnap e Reichenbach. Arthur Pap faz jus ao pragmatismo conceitual de Lewis e Dewey - que teriam sido suas principais influências - no primeiro e segundo capítulos da primeira parte de The A Priori in Physical Theory, intitulada "The Functional A Priori". A teoria funcional do a priori é aplicada à mecânica newtoniana na segunda parte da tese, intitulada "Application of the Functional Theory of the A priori to Newtonian Mechanics", que consiste de mais três capítulos (cf. também Huffermann 2019b). A partir do terceiro capítulo da primeira parte, Pap discute como leis empíricas podem servir como definições de conceitos básicos de uma disciplina. A argumentação se dá em termos gerais, tendo a Física como um todo como escopo, a partir de uma perspectiva mais abstrata e menos conectada a casos específicos. A discussão prossegue no quarto capítulo exemplificando e expandindo pontos do capítulo anterior ao tratar de casos específicos da Física. Em determinada medida a interpretação aqui apresentada colapsa ambos os momentos argumentativos, privilegiando os casos tratados pelo autor.

Pap afirma que analogamente à axiomática formal, certos conceitos (aqueles mais fundamentais) da Física seriam definidos de acordo com certos modos de operar com eles, sendo esses modos determinados em alguns casos posteriormente a considerações experimentais (o caso a ser tratado a seguir é um exemplo). Ele traça a analogia de maneira clara na seguinte passagem:

No sistema de Hilbert, os axiomas que descrevem relações entre elementos das classes denotadas pelos termos primitivos "ponto", "linha reta", "plano", são as definições das noções primitivas. Por esse método de definição implícita, essas noções geométricas são, de fato, privadas de todo conteúdo intuível; um "ponto" pode bem significar um trio ordenado de números reais, como pode ser a intersecção entre dois raios de luz. Encontramos, entretanto, uma conceptualização análoga na física, na qual "onda", por exemplo, é definida como qualquer solução de um certo tipo de equação diferencial, de tal modo que o conceito de onda vem a ser aplicado a fenômenos que não eram originalmente denotados pelo termo concreto "onda". Assim sendo, as equações de Maxwell para o campo eletromagnético são satisfeitas pela luz, 
assim como pela eletricidade; nesse aspecto constituem uma definição implícita de uma classe isomórfica de classes em um sentido análogo ao qual os axiomas de Hilbert “definem”. (Pap 1968[1946], p.19, itálico no original)

As equações de Maxwell "definem” onda na medida em que estipulam critérios para operar cientificamente com esse conceito, para determinar as interações e transformações relevantes no estudo dos fenômenos ondulatórios. Se um fenômeno é tratável através das equações em questão, trata-se de um caso ondulatório, ondas "reais" são aquelas tratáveis pelas equações; similarmente, "ponto" é algo determinado a partir de certas relações, tais quais "entre" e "congruente". Pode-se aclarar o cerne da analogia entre a axiomática formal e a teoria física voltando ao tópico do papel definicional que certas generalizações indutivas podem assumir no percurso da investigação empírica. O ponto central é que tais generalizações exibem o uso preciso e empiricamente manipulável dos conceitos, desse modo fornecendo parâmetros para investigação e ampliação do conhecimento científico. Os princípios servem como a base que permite a articulação dos conceitos empíricos e o desenvolvimento de novos conceitos empíricos. Pap entende esse processo como o "funcionamento analítico" dos princípios "Esse processo em direção à analiticidade é ao mesmo tempo um processo de refinar e articular conceitos empíricos” (Pap 1968[1946], p.20). A noção de funcionamento analítico pode ser entendida à luz de como Pap compreende certos casos empíricos particulares; consideremos a seguir o "funcionamento analítico" da Lei de Hooke.

A Lei de Hooke é uma lei da Mecânica de sólidos relacionada à elasticidade de corpos, servindo para calcular a deformação causada a corpos proporcionalmente à força exercida sobre eles. O sentido de "analítico" é definido por Pap de maneira contrafactual: “Para cada $x$, se $x$ é $S$, então $x$ é $P$ ' é válido como uma implicação analítica se 'há $x$ tal que $x$ é $S$ e não é $P$ ' não é somente falso, mas implica, em termos de regras de inferência especificadas, uma contradição" (Pap 1968[1946], p.10). Não é necessário tratar das transformações das leis empíricas em definições de conceitos centrais de uma determinada investigação do modo formalizado que Pap demanda na tese de 1946. As demandas normativas de Pap, apesar de justificadas dado o contexto de elaboração da teoria, são exacerbadas se consideramos a história posterior dos projetos de desenvolver uma lógica da indução e da confirmação de hipóteses científicas (cf. Goodman, 1983).

Propomos compreender como leis empíricas funcionam como definições de modo modal: uma vez entrincheirada (enrijecida como critério), uma lei empírica delimita o que é possível, de modo que uma instância "real" de $S$ necessariamente é uma instância de $P$. Trata-se de uma necessidade hipotética: ${ }^{3}$ assumindo determinada lei como critério, elimino certas possibilidades de verificação experimental. A ideia é que endossar um conjunto bem articulado de sentenças é condição para a cognoscibili- 
dade de certas verdades empíricas. Essas condições de cognoscibilidade delimitam os critérios a partir dos quais a investigação torna-se possível. Todavia, é importante ter em mente que esses critérios são revisáveis diante de evidência recalcitrante (Pap 1968, p.11).

Com relação a Lei de Hooke, Pap solicita que se imagine um experimento que consiste em uma série de testes empíricos de aplicação de uma força sobre um arame. Visualmente é útil pensar em tal arame como uma mola. O objetivo do experimento é estabelecer uma regularidade expressa por uma equação contendo duas variáveis. De acordo com esse experimento, num plano cartesiano as informações obtidas nos testes seriam organizadas do seguinte modo: as ordenadas corresponderiam à força aplicada sobre a mola enquanto as abcissas seriam interpretadas como "valores de alongamento causados pela aplicação da força (ou vice-versa)" (Pap 1968[1946], p.29). Podemos imaginar que o modo pelo qual a força seria aplicada consiste no sucessivo aumento do peso de um objeto amarrado a uma mola de metal, verificando o quanto a mola se alonga em função da força exercida sobre ela. Alguém, depois de um número suficiente de testes "encontrará que os pontos representando os resultados das medições se organizam aproximadamente em linha reta" (Pap 1968[1946], p.29). Por extrapolação, e pressupondo a ausência de erro sistemático, ${ }^{4}$ é possível traçar uma linha no plano cartesiano em questão e interpretar essa construção geométrica como uma lei que correlaciona a força aplicada à deformação do arame, estabelecendo que uma é proporcional à outra. A regularidade estabelecida pela equação seria que dado um determinado escopo de variação, em que tudo mais se mantém constante, a força aplicada é proporcional à deformação do arame. Tendo imaginado esse experimento, Pap pede que consideremos em seguida o seguinte:

Suponha agora que tendo verificado a Lei de Hooke pela sucessiva adição de pesos ao arame de teste, encontramos ao aplicar novos pesos pontos desviando da linha reta para além do que é justificado pela pressuposição de certo erro acidental. Provavelmente, a discrepância não será interpretada pelo físico como uma refutação da Lei de Hooke, mas como uma indicação que o limite elástico do arame foi excedida. Enquanto ele argumenta 'força aplicada não é proporcional à deformação, consequentemente, o limite elástico foi excedido', ele está empregando a Lei de Hooke como um critério definicional, dado que da falsidade do consequente infere que as condições que delimitam a aplicabilidade da Lei de Hook não estão satisfeitas. (Pap 1968, p.30)

Pap está afirmando que a Lei de Hooke, em certos contextos, determina - ao menos parcialmente - que fenômeno está a ocorrer. Dado um contexto teórico, que envolve entre outras coisas prescrições para o uso de instrumentos, a Lei de Hooke faz parte do que Pap denomina "critérios de classificação válida" (Pap 1968, p.16) de fenômenos. O que explica esse estatuto diferenciado não é sua irrevisabilidade 
absoluta, visto que princípios funcionalmente a priori como a Lei de Hooke não possuem essa propriedade. A lei pode ser tomada como critério para determinar o limite elástico de um sólido, sendo um ponto de partida de uma investigação científica, que pode ter como ponto de chegada certos invariantes empíricos. Esses invariantes, ao serem tomados como critérios, estabelecem resultados similares, sendo possível inclusive (re)estabelecer a regularidade expressa na Lei de Hooke a partir de outras leis da mecânica de sólidos que versam sobre o conceito de "limite elástico" (Pap 1968, p.30). Como já mencionado, as leis de uma disciplina devem ser entendidas como uma rede:

Leis físicas formam, desse modo, uma rede, de tal maneira que há sempre alternativas disponíveis para a medição de propriedades físicas. Portanto, uma lei que é pressuposta como princípio de interpretação em um experimento pode ela mesma ser testada por outro experimento, no qual outras leis funcionam como princípios de interpretação. (Pap 1968, p.35, itálicos no original)

Voltando à compreensão modal de analiticidade funcional: assumindo a lei como critério, uma série de estados de coisas torna-se impossível: que deformação de um sólido seja o quadrado da força, que seja inversamente proporcional à força, etc. Além disso, é a partir de seu estabelecimento como princípio que decorre o desenvolvimento e a articulação de conceitos empíricos como, por exemplo, o conceito de limite elástico. A partir da Lei de Hooke são estipulados critérios para operar cientificamente com esse conceito, para determinar as interações e transformações relevantes dignas da atenção do investigador. O conjunto formado com as demais leis da mecânica de sólidos forma um sistema de descrição, manipulação e intervenção de fenômenos empíricos. O cerne da proposta de Pap é o seguinte: os princípios que teriam um estatuto diferenciado têm a função de univocamente associar certos elementos teóricos a dados empíricos.

Assim, a partir da teoria funcional do a priori afirma-se que as leis da física formam um conjunto de alternativas a partir das quais é possível o rastreio de propriedades físicas, de modo que a medição de propriedades físicas pressupõe certos parâmetros de interpretação. As mudanças em como conceitua-se o mundo são feitas levando em consideração mais do que o interesse em ampliar a lista de verdades conhecidas. É falso que essa tese, compatível com a "virada histórica" já mencionada, acarreta que a mudança é arbitrária ou irracional (retornamos a esse ponto ao discutir a resposta de Pap a possibilidade do "Fósforo Gêmeo"). O insight principal da teoria funcional do a priori é que certos princípios se transformam em definições quando usados como critério para estabelecer uma caracterização legítima de um fenômeno pertencente a certa categoria de fenômenos. Trata-se de uma perspectiva que não dá suporte ao essencialismo acerca de espécies naturais como "onda" e "água". A atribuição dos predicados ser-água e ser-onda não é correta se e somente se está de acordo 
com a extensão (conhecida ou não) dos termos, mas envolve também um sistema articulado de termos, que ao serem adquiridos nos permitem falar precisamente de "água" e "onda".

\section{Terra Gêmea e Fósforo Gêmeo}

Nesta seção examinaremos o célebre experimento de pensamento da Terra Gêmea de Putnam, encontrado em "The meaning of 'meaning", e que, sob certa leitura, dá suporte à ideia de que a investigação de espécies naturais desvela essências. Contudo, antes de prosseguir é importante ressaltar que tal leitura não pode ser atribuída diretamente a Putnam. Como aponta Hacking (2007), o pensamento de Putnam acerca de espécie naturais modificou-se ao longo de mais de 30 anos, sendo retificada ao longo do processo, o que inclui a afirmação que água é necessariamente $\mathrm{H}_{2} \mathrm{O}$ (eventualmente abandonada). $\mathrm{O}$ que ele parece ter defendido é que estruturas subjacentes e não superficiais determinavam as espécies naturais, mas o que contava como uma espécie natural era relativo a interesses. Se isso é caso, Pap e Putnam convergem mais do que divergem acerca desse tópico. Ainda assim, é possível tratar as contribuições de Putnam sobre espécies naturais em conjunto com as considerações de Kripke em Naming and Necessity (Sharrock e Read, 2002). Ambos os autores contribuíram significativamente em mais de uma discussão filosófica ao longo do século $X X$. Não cabe dentro do escopo desse artigo uma discussão minuciosa de suas célebres obras. O que destacamos é que a assim chamada teoria Kripke-Putnam ou Putnam-Kripke de designadores de espécies naturais foi tomada como uma defesa do essencialismo acerca de espécies naturais. É contra essa teoria ou possibilidade teórica, possivelmente não defendida integralmente por nenhum dos autores, que nos posicionamos. Sem a pretensão de discutir a filosofia de Putnam em sua totalidade, restrinjamos a análise ao experimento de pensamento da Terra Gêmea encontrado em "The meaning of 'meaning"' (Putnam, 1975). Apresentaremos o experimento de pensamento, uma leitura essencialista do mesmo e um caso análogo imaginado por Arthur Pap (nomeado por nós "Fósforo Gêmeo").

Putnam pede que imaginemos a existência de um planeta, a Terra Gêmea, que é virtualmente idêntico à Terra, a única diferença é a composição molecular do líquido inodoro e incolor que usam para matar a sede. Podemos imaginar que falam os mesmos idiomas que nós aqui na Terra e que basicamente sua ciência é igual à nossa. A única diferença é que na Terra Gêmea "água" não designa $H_{2} 0$, mas um composto muito complexo que é idêntico à água em todas as suas propriedades exceto sua composição química, uma fórmula muito longa que, por economia, é abreviada como $X Y Z$ (Putnam 1975, p.223). Nos oceanos, rios e mares o líquido encontrado em alta concentração é $X Y Z$. A chuva é $X Y Z$ caindo do céu. Consequentemente, nesse ce- 
nário, a extensão da palavra "água" é distinta na Terra e na Terra Gêmea: "água"-t designa $\mathrm{H}_{2} \mathrm{O}$ e "água"-tg designa $X Y Z$. Segundo Putnam, se cientistas da Terra fossem até a Terra Gêmea e examinassem uma amostra da substância que parece $\mathrm{H}_{2} \mathrm{O}$, mas que é $X Y Z$, concluiriam que na Terra o termo "água" significa $\mathrm{H}_{2} \mathrm{O}$ mas na Terra Gêmea "água" significa XYZ (Putnam 1975, p.224). O que permite os habitantes de ambos os planetas diferenciar as amostras é seu conhecimento compartilhado de química, reconhecendo as substâncias como distintas: água-t e água-tg. Contudo, podemos imaginar a Terra e a Terra Gêmea no ano de 1750, quando a composição química do líquido chamado "água" em cada planeta era desconhecida em ambos os planetas. Nesse período, um indivíduo terráqueo e um indivíduo gêmeo-terráqueo, aos estarem diante de um rio em seus respectivos planetas, formam as mesmas crenças: estão diante de uma substância conhecida como "água", que mata a sede, é útil para cozinhar e para a higiene. Os indivíduos formam as mesmas crenças de acordo com o entendimento de "estado psicológico" internalista que Putnam endossa em "The meaning of 'meaning"'. Se dois indivíduos podem associar exatamente a mesma intensão a uma certa palavra e ela ter diferentes extensões, para Putnam (1975), não é problemático descrever esses indivíduos como tendo o mesmo estado psicológico (mesmo a palavra empregada possuindo referentes distintos). Portanto, basta que a intensão do termo "água" operante em ambos os indivíduos seja a mesma para que possam ter as mesmas crenças (o que é estipulado como sendo o caso para o cenário em 1750). ${ }^{5}$ Dado o escopo desse artigo, não discuto o mérito dessa caracterização do que são estados psicológicos. O ponto é que mesmo concedendo isso a Putnam, a legitimidade do experimento de pensamento ainda é impugnada.

Nenhum dos dois teria o conhecimento dos compostos químicos com os quais interagem. De tal modo, apesar de terem as mesmas crenças, os mesmos estados psicológicos, eles usam o mesmo termo para se referir a diferentes substâncias, $\mathrm{H}_{2} \mathrm{O}$ e $X Y Z$. Com esse cenário Putnam busca mostrar que a continuidade da referência de um termo é possível devido à existência de uma cadeia histórico causal que conecta o uso do termo a uma determinada amostra do tipo de coisa que pretendemos denotar com o termo (Putnam 1975, p.225). Os indivíduos não sabem, e não é necessário que saibam, que se referem a água-t e água-tg, ou a $\mathrm{H}_{2} \mathrm{O}$ e $X Y Z$, respectivamente. Um corolário extraído por Putnam é a estabilidade da referência de termos teóricos ao longo do tempo. A referência de "água" não muda, entre indivíduos na Terra e na Terra Gêmea, entre 1750 e o tempo presente. De acordo com uma leitura que aceita a legitimidade do experimento de pensamento, o que mudou com a revolução química foi apenas a intenção do falante. Desse modo, o que é relevante para a prática (e progresso) da ciência, a referência dos termos de espécies naturais, se mantém constante. De acordo com uma imagem essencialista, o progresso da ciência química terráquea foi o desvelamento da essência de água-t $\left(\mathrm{H}_{2} \mathrm{O}\right)$, assim como o progresso da ciência química gêmeo-terráquea foi o desvelamento da essência de água-tg $(X Y Z)$. 
Se isso é o caso para o termo "água", não há razões para não pensar as ciências em geral do mesmo modo.

O experimento de Putnam é de 1975, mas em 1946 Arthur Pap já tinha pensado em uma situação análoga, embora com propósitos distintos. Uma crítica possível à posição de Pap acerca dos princípios da ciência é que a suposta rede de alternativas não dá conta da objetividade científica. $\mathrm{O}$ que o cientista tem a sua disposição seria uma rede a partir da qual ele poderia de maneira não especificada e arbitrária escolher qual dessas alternativas serão privilegiadas; o que funciona como critério e o que é resultado experimental esperado no seu percurso investigativo é uma questão de escolha aberta a multiplicidade considerável de possibilidades. O contexto em que um princípio funciona analiticamente muda não apenas no percurso de desenvolvimento de uma disciplina, mas de práticas e escolhas individuais do pesquisador. Não há posicionamento direto e textual de Pap acerca dessa questão, mas é possível formular uma resposta a essa preocupação. Curiosamente, o autor considera como adversária a perspectiva oposta, aquela que enfatiza a prática de "imunização" de certas leis contra a refutação empírica direta. Para tratar do ponto aqui levantado é preciso averiguar a relação entendida por Pap entre a experiência e as leis de teorias científicas bem estabelecidas, assim como sua resposta para aqueles que afirmam de maneira não qualificada que uma lei é mantida frente à experiência por definição. O filósofo propõe algo que poderíamos chamar de hipótese do "Fósforo gêmeo" para tratar a perspectiva considerada por ele adversária:

Convencionalistas que enfatizam a possibilidade de tornar leis irrefutáveis ao tratá-las como definições são propensos a desconsiderar o fato que nos procedimentos científicos atuais não é legítimo resolver um conflito entre lei e experiência, a não ser que a aparente falha da lei possa ela mesma ser explicada em termos de erro sistemático. Deixe-me ilustrar essa característica importante do método científico pela lei "O ponto de fusão do Fósforo é $44^{\circ}$ C". Suponha que encontramos uma substância que exibe todas as propriedades do Fósforo, exceto seu ponto de fusão; por definição, podemos argumentar, não é Fósforo. (Pap 1968[1946], p.31, itálicos no original).

O "convencionalista" seria aquele que atribui certa imunidade às leis físicas ao presumir que elas podem ser consideradas definições de modo quase idêntico, senão idêntico, as definições em sistemas formais. Pap aproxima os princípios das ciências de definições das ciências formais, mas nunca os equipara. No caso em que encontrássemos uma substância que exibisse todas as propriedades do Fósforo, exceto seu ponto de fusão, o convencionalista estaria disposto a afirmar que não se trata de Fósforo simplesmente por não estar de acordo com a definição de Fósforo - aquilo cujo ponto de fusão é $44^{\circ} \mathrm{C}$ : uma simples questão de aplicar a definição. Como veremos a seguir, não é desse modo que Pap entende a questão. Podemos elaborar a posição do convencionalista pensando a partir do experimento de Putnam. Antes da descoberta 
desse Fósforo gêmeo, Fósforo-g, cujo ponto de fusão é distinto do Fósforo, alguém poderia ter as mesmas crenças com relação a ambas as substâncias, de modo análogo aos indivíduos na Terra e na Terra Gêmea. A diferença nesse caso é que toda vez que o indivíduo formava uma crença acerca do Fósforo-g pensando ser Fósforo, formava uma crença falsa. O que essa nova descoberta possibilita é uma revisão das suas crenças rumo a um conhecimento mais preciso da natureza. A referência do termo "Fósforo" não muda com a descoberta do Fósforo-g, e, se estamos de acordo com a visão essencialista, afirmaríamos que descobrimos uma nova essência desconhecida pela teoria química até então.

\section{Abuso de substâncias gêmeas e a fixação da referência de termos científicos}

Como, com base na prática científica, devemos analisar os cenários da Terra Gêmea e do Fósforo Gêmeo? Primeiro, examinemos como Pap compreende o caso do Fósforo Gêmeo:

Suponha que encontremos uma substância que exibe todas as propriedades do fósforo, exceto seu ponto de fusão; por definição, alguém pode argumentar, não é fósforo, logo a lei se mantém válida. Contudo, a ciência em seus estágios avançados não define substâncias através de uma coleção acidental [haphazard] de propriedades observáveis. [... ] Ao recusar-se a classificar a substância desse tipo como fósforo, implicitamente declara-se a falha da lei (correlacionando a densidade e o ponto de fusão de um sólido) que está encarnada, por assim dizer, na própria definição de fósforo. Alguém afirma a existência de fósforo numa substância que exibe algumas características de fósforo, mas ainda assim deixa de [fails to] exibir características causalmente dependentes. Para explicar tal anomalia alguém pode, por exemplo, referirse a lei que [afirma] que o ponto de fusão de uma substância depende da pressão à qual a substância é submetida, e tentativamente avançar a hipótese que a substância em questão não derreteu a $44^{\circ}$ porque a pressão sob a qual fósforo entra em fusão a $44^{\circ}$ não foi experimentalmente realizada. (Pap 1968, p.31).

Na hipótese em que o cientista se depara com uma substância que exibe todas as propriedades do Fósforo exceto seu ponto de fusão, o mesmo não se encontra justificado em afirmar que não se trata de Fósforo somente por definição, ou seja, assumindo dogmaticamente que Fósforo é aquilo que entra em fusão a $44^{\circ} \mathrm{C}$ e verificando que isso não é caso para a substância em questão. Como afirma o autor "a ciência em seus estágios avançados não define substâncias através de uma coleção acidental [haphazard] de propriedades observáveis" (Pap [1946]1968, p.31). Existem propriedades causalmente conectadas ao ponto de fusão de uma substância, como por exemplo, 
sua densidade e a pressão a qual está submetida a substância (a temperatura de $44^{\circ} \mathrm{C}$ é o ponto de fusão do Fósforo relativo à pressão de 1 atmosfera). As definições na ciência devem ter algum valor preditivo, e para isso "o defininens $[\ldots]$ deve ser propriedades causalmente conectadas" (Pap 1968, p.31) Pap afirma que é improvável a existência do Fósforo gêmeo na passagem citada, pois significaria descobrir um erro na lei que associa a densidade de uma substância e seu ponto de fusão.

Entretanto, ao seriamente adotar uma perspectiva que considera de antemão legítima a prática científica, o que é um compromisso da teoria funcional do a priori, é averiguado que uma postura mais incisiva deveria ser tomada. É altamente improvável que as relações previamente estabelecidas entre pressão, densidade e ponto de fusão estejam equivocadas. Pap não considera seriamente a possibilidade da descoberta do Fósforo gêmeo. Pap confia que uma amostra com ponto de fusão de $44^{\circ} \mathrm{C}$ se revelará Fósforo. A sugestão é que se deve buscar uma explicação para a aparente anormalidade daquela amostra de Fósforo "gêmeo", como por exemplo, condições de pressão que explicam o fato de que a substância não muda de estado físico na temperatura em que se espera que mude. As propriedades físicas são estabelecidas de maneira articulada e causalmente dependente. Em decorrência disso, justifica-se que nesse cenário o mais plausível é que condições iniciais de experimentação (a pressão a qual se encontrava a amostra, por exemplo) foram negligenciadas.

Retornando à suposta arbitrariedade da escolha de princípios pode-se enfatizar um aspecto não tratado diretamente por Pap, mas amplamente presente na discussão contemporânea: um cientista é alguém inserido numa determinada comunidade. No seu processo formativo educou-se de modo a identificar uma série de similaridades, desenvolver uma série de expectativas, que se relacionam ao desenvolvimento histórico da comunidade científica da qual faz parte. Portanto, desse mesmo modo herda uma agenda de trabalhos e instrumentos conceituais que justificam suas escolhas, herança que se presume ser aquela que melhor o capacita para o rastreio de propriedades físicas. Julgá-las arbitrárias é não atribuir autoridade epistêmica às comunidades científicas, o que vai na contramão da perspectiva descritivo-normativa da prática científica adotada a partir da "virada histórica" e da ideia de progresso da ciência enquanto avanço a partir de soluções bem sucedidas de problemas teóricos. Ambas essas características, mesmo que não de forma explícita e formuladas nesses termos, se encontram presentes na concepção funcional do a priori.

Retornando à questão de como pensar a aparente descoberta do Fósforo-g, a descoberta efetiva de tal substância implicaria em uma mudança drástica da teoria química. A relação entre o ponto de fusão de uma substância e sua pressão é somente um exemplo, já que "pressão" é ele mesmo um termo teórico associado a outras atribuições de propriedades físicas. A referência do termo "Fósforo" é fixada de modo mais holista do que aquele sugerido por Putnam; a fixação se dá conjuntamente com a referência de diversos termos da teoria química. É difícil imaginar qual seriam os pri- 
meiros passos, mas a descoberta de Fósforo-g ocasionaria uma revolução científica. Arthur Pap não utiliza esse vocabulário. Anteriormente à publicação de $A$ Estrutura das Revoluções Científicas uma imagem da ciência que enfatizava demasiadamente a continuidade de seu desenvolvimento era hegemônica. Como destacamos, Pap não considera seriamente a hipótese do Fósforo Gêmeo.

A conceptibilidade de Fósforo-g não implica a sua possibilidade no mundo em que as leis científicas atuais são verdadeiras (seja esse o mundo atual ou não). A descoberta de Fósforo-g acarretaria a tomada de consciência de que, sem sombra de dúvida, não vivemos no mundo descrito pela teoria química. A resposta kuhniana a cenários de Terra Gêmea é muito similar. Kuhn busca mostrar, de maneira especialmente clara em "Dubbing and Redubbing" (1990), que um mundo em que a Terra e Terra Gêmea existam, com seus respectivos líquidos, é impossível (num sentido que tornaremos preciso). Primeiro, é importante lembrar que o experimento de Putnam pressupõe que a teoria química atual é capaz de descrever verdadeiramente um mundo possível em que $\mathrm{H}_{2} \mathrm{O}$ e $X Y Z$ (água-t e água-tg) existem, possuem as mesmas propriedades fenomenais ou esteriótipo no jargão de Putnam (inodoro, incolor, mata a sede), exceto a composição química. Esse ponto não é irrelevante: isso é o que possibilita o cientista da Terra visitar a Terra Gêmea e afirmar que lá "água" designa $X Y Z$, assim como é o que nos possibilita inferir que em 1750 um indivíduo na Terra e na Terra Gêmea teriam, de acordo com o internalismo mental de Putnam, as mesmas crenças sobre substâncias distintas. Mas como o cientista da terra adquiriu o vocabulário que lhe permite afirmar a fórmula química da água? A resposta de Kuhn, na Estrutura, é que os conceitos científicos são adquiridos a partir de exemplares: "as realizações científicas universalmente reconhecidas que, durante algum tempo, fornecem problemas e soluções modelares para uma comunidade de praticantes de uma ciência". (Kuhn 2012, p.13).

Como mencionado na Introdução, o desenvolvimento da ciência se dá a partir de resoluções de problemas que guiam a resolução de novos problemas. Quando um estudante aprende a aplicar generalizações simbólicas como " $F=m \cdot a$ " em demonstrações matemáticas aplicadas em situações concretas, ele adquire as habilidades de aplicar conjuntamente os termos " $F$ ", " $m$ ", " $a$ " a eventos e propriedades de objetos e como outras generalizações simbólicas podem ser derivadas de $F=m \cdot a$, a partir das relações de semelhança entre as diferentes situações de aplicação. Ao aplicar exemplares na solução de problemas, o aprendiz está sendo treinado para reconhecer novos problemas como os problemas que os exemplares já resolvem. O estudante aprende a pensar em novos problemas de maneira análoga àqueles para os quais o exemplar já possui uma aplicação bem estabelecida. O aprendizado de um vocabulário científico se dá pela aplicação do vocabulário em situações concretas.

Já numa revolução científica, todavia, um dos principais acontecimentos é a mudança de exemplares. Um exemplar que deixou de ser eficiente é substituído por 
outro. Os termos científicos são aprendidos e adquirem seu significado no interior de uma teoria, a partir da aplicação a casos concretos. Se Kuhn (2012) está correto, o que acontece numa revolução científica é um processo (no mais das vezes de algumas gerações) de substituição de exemplares e da matriz disciplinar mais ampla. $\mathrm{O}$ paradigma que substitui o anterior determina outras relações de similaridade, outros problemas e outras soluções. Como são teorias diferentes, e os termos científicos adquirem significado a partir da aplicação a casos concretos, não expressam os mesmos conceitos. Uma consequência disso é que diversos enunciados no paradigma anterior serão incompatíveis com (e intraduzíveis no) ${ }^{6}$ paradigma atual. Além disso, em sua filosofia pós Estrutura Kuhn compreende as teorias científicas como léxicos estruturados constituídos pelos conceitos de uma disciplina (Kuhn 2003, pp.116-7). Os termos teóricos devem ser entendidos no contexto de estruturas taxonômicas em termos de gênero e espécies. O que o cientista sabe não é necessariamente uma definição das espécies relevantes a sua disciplina, o que ele domina é a aplicação correta desse léxico a casos concretos, assim como detém a capacidade de formular enunciados corretos utilizando o léxico. Em outras palavras, a ciência pode ser compreendida em termos da habilidade de usar taxonomias de gêneros e espécies científicas.

Como destaca Ferreira (2019), o que torna possível descrever a natureza a partir de um léxico é um treino da habilidade de reconhecer (mesmo que não de forma explícita) similaridades e dissimilaridades entre objetos, eventos, problemas e soluções de problemas. Diferentes léxicos acarretam diferentes modos pelos quais eventos, objetos, problemas e soluções de problemas são agrupados. Uma maneira de entender as taxonomias é como nos apresentando certos conjuntos de possibilidades, certos mundos possíveis, entendendo "mundos possíveis" como contrafactuais. Se assim as compreendermos, teorias científicas diferentes nos dão acesso a diferentes mundos possíveis, diferentes situações contrafactuais serão endossadas de acordo com o paradigma em que estamos situados. De acordo com os parâmetros estabelecidos pelo léxico certos objetos e eventos são possíveis, e alguns outros são julgados impossíveis. Como afirma Kuhn:

Possuir um léxico, um vocabulário estruturado, é ter acesso ao variado conjunto de mundos que aquele léxico pode ser usado para descrever. Léxicos diferentes, aqueles de diferentes culturas ou diferentes períodos históricos, por exemplo - dão acesso a diferentes conjuntos de mundos possíveis, amplamente, mas nunca inteiramente sobrepostos. (Kuhn 1990, p.300)

Kuhn identifica uma falha na ficção de Putnam que nos autoriza a impugnar a legitimidade do experimento de pensamento. A partir da teoria química moderna não é possível descrever coerentemente um mundo possível em que as substâncias água-t e água-tg coexistem tendo as mesmas propriedades, exceto por sua fórmula química $\left(\mathrm{H}_{2} \mathrm{O}\right.$ e $X Y Z$, respectivamente). Por exemplo, de acordo com a teoria quí- 
mica moderna água-tg seria muito pesada para evaporar nas condições em que água-t evapora:

Os termos ' $X Y Z$ ' e ' $\mathrm{H}_{2} \mathrm{O}$ ' são retirados da teoria química moderna, e aquela teoria é incompatível com a existência de uma substância com propriedades proximamente iguais as da água, mas descrita por uma fórmula química elaborada. Tal substância iria, entre outras coisas, ser muito pesada para evaporar a temperaturas normais terrestres.[... ] Dentro do léxico da química moderna, um mundo contendo tanto a nossa Terra quanto a Terra Gêmea de Putnam é lexicalmente possível, mas a asserção composta que descreve é necessariamente falsa. Somente com um léxico estruturado diferentemente, um léxico moldado para descrever um tipo de mundo muito diferente, alguém, sem contradição, poderia descrever o comportamento de ' $X Y Z$ ', e naquele léxico ' $\mathrm{H}_{2} \mathrm{O}$ ' pode não se referir ao que chamamos 'água'. (Kuhn 1990, p.310)

Num mundo em que nosso léxico é estruturado de modo a afirmar que água é $\mathrm{H}_{2} \mathrm{O}$, é impossível descrever o comportamento de $X Y Z$ sem entrarmos em contradição. Se os parâmetros do que é possível forem ao menos parcialmente determinados pela teoria química (se endossamos a teoria química), não existe e não pode existir $X Y Z$. Como afirma Kuhn com bom humor, os cientistas terráqueos, ao examinarem $X Y Z$, afirmariam com espanto "De volta à lousa! Algo está terrivelmente errado com a teoria química" (Kuhn 1990, p.310). A atribuição de propriedades feita a partir de uma teoria científica é extremamente sistemática: "O léxico requerido para etiquetar atributos como ser- $\mathrm{H}_{2} \mathrm{O}$ [...] é rico e sistemático. Ninguém pode usar nenhum dos termos que ele contém sem ser capaz de usar muitos outros" (Kuhn 1990, p.312). Similar a "Fósforo", a referência do termo "água" é fixada de modo mais holista do que aquele sugerido por Putnam, conjuntamente com a referência de diversos termos da teoria química. Resumindo, não temos acesso a um mundo possível em que existam tanto água-t como água-tg se endossamos a teoria química moderna.

\section{Considerações Finais}

Arthur Pap e Thomas Kuhn, de forma independente e em diferentes metades do século $X X$, desenvolveram teorias que nos autorizam a afirmar que a referência de termos que fazem parte de um léxico científico se dá de modo holista. Para Kuhn, de modo explícito, a referência de um termo é fixada conjuntamente com a referência de muitos outros sistematicamente relacionados. Para Pap a questão não é diretamente tematizada, mas à luz de desenvolvimentos posteriores em filosofia da ciência podemos pensar a teoria funcional do a priori de modo a chegarmos numa resposta similar à de Kuhn. Em especial, a partir das considerações de Pap acerca do 
que chamamos "Fósforo Gêmeo" e de sua caracterização das leis científicas como formando uma rede de alternativas para investigação de propriedades empíricas fomos capazes de tornar explícita uma concepção subjacente a sua teoria. Em linhas gerais, propriedades físicas são estabelecidas de maneira articulada e causalmente dependente, de modo que ao atribuir uma propriedade física a uma amostra atribuímos conjuntamente uma série de outras sistematicamente organizadas. Em ambos, cada um à sua maneira, encontramos uma tese holista sobre a fixação da referência de termos científicos.

Em que sentido tal análise da fixação da referência, comum a Pap e Kuhn, oferece razões em favor da recusa do essencialismo de espécies naturais? A partir das considerações de Kripke e Putnam acerca da fixação da referência podemos ser tentados a pensar que a referência de termos (tanto nomes próprios quanto termos do léxico científico) é dada por um agregado de propriedades essenciais. O batismo, seja de uma pessoa ou de uma substância, seria a associação de um proferimento linguístico a um agregado de propriedades que a coisa deve ter para ser aquilo que é. Isso é o caso mesmo quando o batismo ocorre por meio de uma descrição falsa, já que o que é relevante para fixar a referência é a extensão do termo. Os termos "Água", "João", "Oricalco" estão associados a propriedades essenciais quando fixamos sua referência, sejam essas propriedades quais forem, sejam elas conhecidas ou não. Interessados em conhecer melhor o mundo e tendo a imagem essencialista como guia, nossa tarefa é examinar as propriedades das coisas e separar o joio do trigo, separar as propriedades essenciais das propriedades meramente acidentais. O que os argumentos de Pap e de Kuhn sugerem é que a tarefa descrita acima seria impossível. Evitamos, propositalmente, discutir a aplicação da teoria causal da referência a nomes próprios. Pap não diz nada que possa ser interpretado contra ou a favor de tal aplicação e Kuhn (1990, p.312) considera a aplicação a nomes próprios não problemática e bemsucedida. A questão para Kuhn é a aplicação para o vocabulário científico. Termos de espécies naturais como "ouro" e "água" são termos curtos (e nesse aspecto similares a nomes próprios) que parecem denotar propriedade essenciais, como ser- $\mathrm{H}_{2} \mathrm{O}$. Contudo, uma análise mais detalhada nos mostra que propriedades como ser- $\mathrm{H}_{2} \mathrm{O}$ e ter-o-número-atômico-79 são associadas aos seus respectivos termos em bloco. Para atribuir a "água" ser- $\mathrm{H}_{2} \mathrm{O}$ temos que atribuir a "água" "evapora a $100^{\circ} \mathrm{C}$ à pressão de 1 atmosfera". Precisamos adotar um vocabulário altamente sistemático que não nos autoriza a distinguir, entre estrutura molecular e ponto de ebulição, qual propriedade seria acidental e qual seria essencial. Adotando o vocabulário de Kuhn: em períodos de ciência normal a referência dos termos científicos (o que inclui designadores científicos de espécies) é dada pelo paradigma, mantendo-se constante ou rígida. Contudo, em períodos de revoluções científica espécies científicas podem ser redefinidas, de modo a conjuntamente mudarem sua referência. Os termos de espécies empregados nas ciências designam rigidamente na maior parte do tempo, nos 
períodos de ciência normal, mas são vulneráveis a revoluções científicas. Arthur Pap, antes de Putnam e Kuhn, descreve sua abordagem do conhecimento científico como dinâmica ao se considerar um discípulo de Poincaré (Pap [1946]1968, p.vii). O que ele teria a nos dizer sobre a fixação da referência dos termos científicos é que ela não é arbitrária e se dá em rede, propriedades físicas são estabelecidas de maneira altamente sistemática. Fixar a referência de um termo científico é fixar a referência de muitos outros ao aderir a um sistema articulado de atribuições de propriedades físicas. Com base na prática científica, Pap e Kuhn nos oferecem boas razões para rejeitar a extensão da teoria causal da referência a designadores de espécies naturais. As mesmas razões também possibilitam a rejeição da imagem essencialista acerca de termos de espécie e as consequências dessa imagem para nossa compreensão do empreendimento científico.

Por fim, gostaria de explicitar considerações de cunho histórico. Podemos ver claramente que a "virada histórica" em filosofia analítica da ciência é um processo muito mais contínuo do que comumente pensado. O adjetivo "analítico" é relevante aqui. É no mais das vezes negligenciado que a filosofia da ciência francófona já era informada pela prática científica e sua história muito antes dos nomes mencionados por Kuhn (2003), como Koyré, Duhem e Poincaré. A virada histórica mencionada neste artigo é comumente atribuída a publicação de A Estrutura das Revoluções Científicas, mas o que foi dito até aqui deixa claro o exagero de interpretar essa afirmação de modo literal. O que um olhar mais atento à filosofia de Arthur Pap mostra é como se deu o intercâmbio entre as tradições francófona e anglófona. A própria ideia de uma virada histórica se torna exagerada se a entendemos como um processo repentino e descontínuo. A filosofia da ciência analítica substancialmente informada pela prática científica e sua história remonta pelo menos até os anos 40 do século $X X$.

\section{Referências}

Ferreira, R. S. 2019. Sobre a vulnerabilidade da designação rígida: a crítica kuhniana à Teoria Causal da Referência. Princípios: Revista de Filosofia 26(51): 205-224.

Feyerabend, P. K. 1962. Explanation, reduction, and empiricism. University of Minnesota Press, Minneapolis. Retrieved from the University of Minnesota Digital Conservancy, http://hdl. handle.net/11299/184633.

Friedmann, M. 2001. Dynamics of Reason: The 1999 Kant Lectures at Stanford University. Stanford: CSLI Publications.

Friedmann, M. 2010. Synthetic History Reconsidered. In: M. Domski and M. Dickson (eds.) Discourse on a New Method: Reinvigorating the Marriage of History and Philosophy of Science, pp.571-813. Chicago and La Salle, IL: Open Court.

Friedmann, M. 2011a. Extending the Dynamics of Reason. Erkenntnis 75(3): 431-44.

Friedmann, M. 2011b. Reconsidering the dynamics of reason: Response to Ferrari, Mormann, Nordmann, and Uebel. Studies in History and Philosophy of Science 43: 43-57. 
Goodman, N. 1983. Facts, fiction and forecast. Cambridge: Harvard University Press.

Hacking, I. 2007. Putnam's Theory of Natural Kinds and their names is not the same as Kripke's. Principia 11(1): 1-24.

Hacking, I. 1993. Working in a new world: The taxonomic solution. In: P. Horwich (ed.) World Changes: Thomas Kuhn and the Nature of Science, pp.275-310. MIT Press.

Huffermann, J. D. 2019a. Aspectos constitutivos do conhecimento científico a partir da Teoria Funcional do A Priori. Dissertação de Mestrado disponível em http://hdl.handle.net/10183/194455

Huffermann, J. D. 2019b. O Princípio Da Inércia É Relativamente/Funcionalmente A Priori?. PÓLEMOS - Revista De Estudantes De Filosofia Da Universidade De Brasília 8(16): 75-98.

Kuhn, T. 1990. Dubbing and redubbing: The vulnerability of rigid designation. In: W. Savage; J. Conant; J. Haugeland (eds.) Minnesota Studies in the Philosophy of Science, pp.58-89. University of Minnesota Press.

Kuhn, T. 2003. O Caminho Desde a Estrutura. Trad. Cezar Augusto Mortari. São Paulo: Editora UNESP.

Kuhn, T. 2012. The Structure of Scientific Revolutions. 4th Edition. Chicago: Chicago University Press.

Krikpe, S. 1980. Naming and necessity. Cambridge: Harvard University Press.

Pap, A. 1943. On the Meaning of Necessity. Journal of Philosophy 40(17): 449-58.

Pap, A. 1944. The Different Kinds of A Priori. The Philosophical Review 50(5): 465-84 .

Pap, A. 1946[1968]. The A Priori in Physical Theory. Reimpressão $1^{a}$ ed. Nova York: Russell \& Russell.

Preston, J. 2020. Paul Feyerabend. In: E. N. Zalta (ed.) The Stanford Encyclopedia of Philosophy (Fall 2020 Edition). https://plato.stanford.edu/archives/fall2020/entries/feyerabend/

Putnam, H. 1975. Mind, language and reality: philosophical papers vol.2. Cambridge: Cambridge University Press.

Sharrock, W.; Read, R. 2002. Thomas Kuhn's Misunderstood Relation to Kripke-Putnam Essentialism. Journal for General Philosophy of Science 33(1): 151-8.

\section{Notas}

${ }^{1}$ Agradeço a um dos pareceristas por essa observação.

${ }^{2}$ Entre 1953-1954, Feyerabend foi assistente de Arthur Pap em Viena (Preston, 2020). O importante artigo "Explanation, reduction, and empiricism" data de 1962, assim como a Estrutura de Kuhn.

${ }^{3}$ O próprio Pap usa a expressão "necessidade hipotética" em dois artigos (Pap 1943 e 1944) e menciona que noções desse tipo remetem a considerações feitas por Aristóteles.

${ }^{4} \mathrm{Um}$ erro sistemático é aquele que pode ser eliminado ao ajustarmos as hipóteses auxiliares. Trata-se de um erro eliminável através do controle dos fatores que perturbam as realizações do experimento. Por exemplo, um problema na calibragem dos instrumentos pode levar a medições fora do esperado, mas se o cientista sabe precisamente qual é o problema, ele pode recalcular qual deveria ser o resultado do experimento de acordo com a calibragem dos instrumentos de que ele dispõe naquele momento.

${ }^{5}$ Agradeço a um dos pareceristas pela atenção trazida a esse ponto. 
${ }^{6}$ A não tradutibilidade ou incomensurabilidade entre paradigmas é um tema que perpassa a obra de Kuhn, mas que não será diretamente tematizado neste artigo.

\section{Agradecimentos}

Aos pareceristas e ao corpo editorial por seus excelentes comentários e sugestões. À CAPES pela bolsa de aprimoramento pessoal que permitiu o desenvolvimento dessa pesquisa. Ao colega Rodrigo Sabadin Ferreira, por comentários a versões anteriores desse trabalho. À professora Gisele Dalva Secco, entre outras coisas, pela constante inspiração e por me apresentar Arthur Pap. Ao professor Paulo Faria pela excelente disciplina sobre tipos naturais ministrada no PPGFIl/UFRGS. 